\title{
Exploring the Relationship between Information and Communication Technology Collective Behaviors and Sense of Community: An Urban Refugee Analysis
}

\section{Structured Abstract}

Purpose

Helping others use information and communication technologies (ICTs), such as mobile phones, can be beneficial for individuals and communities. In urban refugee communities, displaced and living far from home, collective behaviors with mobile phones can generate a sense of belonging. We explore the potential for these offline behaviors to generate a sense of community among urban refugees.

\section{Design/Methodology/Approach}

Using quantitative evidence, we examined the relationship between collective behaviors, such as sharing or helping with a mobile phone, and sense of community. We analyzed survey data collected from urban refugees in Rwanda via multiple regression to test hypotheses related to the impact of collective behaviors on sense of community, as well as the mediating role of ICT self-efficacy and gender.

\section{Findings}

Our findings suggest collective behaviors with mobile phones have a positive relationship with sense of community, driven primarily by providing assistance as compared to sharing. ICT self-efficacy was positively related to sense of community. However, collective behaviors' impacts differed by gender, suggesting that social dynamics influence this relationship.

\section{Originality/Value}

While extant literature highlights the various roles of mobile phones in refugees' lives, less is known about the social aspects of use and its potential to help overcome isolation by 
fostering a sense of community. We extend this literature to a novel context (urban refugees in the Global South), testing a model that incorporates other factors that may play a role (e.g. self-efficacy, gender). These findings are valuable to urban refugees, due to difficulties in re-building a sense of community and increased ICT access.

\section{Introduction}

Information and communication technology (ICT) collective behaviors, such as sharing and providing assistance, expand access to and use of these technologies (Best et al., 2012; Burrell, 2010; Walton et al., 2012). They occur in the use of a variety of devices, including desktop computers, tablets, and particularly mobile phones. The global ubiquity of mobile phones has not only diversified users, including young and old, rich and poor, but devices as well. Use of older feature phones continues, particularly in lower-income countries, while newer, increasingly complex, smartphones are growing in global popularity. As users and devices proliferate, family, friends and even strangers provide and receive assistance and, in a pinch, may even lend a device.

For the displaced, community belonging is one of the first elements of life sacrificed. Therefore, it is imperative for scholars and humanitarian agencies to explore and contribute to refugees' efforts to re-build some semblance of community. As Amanda Alencar (2020) suggests in their review of refugee and mobile communications literature, this is a needed avenue of scholarship: "[f]uture studies should explore more collective processes and the power dynamics involved in the appropriation of mobile technologies by different migration actors."

As ICT ubiquity becomes the norm, it is increasingly commonplace for the displaced to have access to ICTs, and for these devices to form an integral part of daily life, just as they likely did before fleeing their homelands. The integration of ICTs into a community's social fabric connects social impacts to ICT use, yielding a rich body of qualitative scholarship on this relationship. Such studies examine for example, how ICTs impact interactions with a host community (Kang et al., 2017), information-seeking behaviors 
(Aléncar and Tsagkroni, 2019; Coles-Kemp and Jensen, 2019), and emotional and mental wellness (Leurs, 2019; Shah et al., 2019), as well as the integration of ICTs into physical existence (Gough and Gough, 2019; Lintner, 2020). While these studies yield nuanced theory, to date there is a lack of quantitative evidence of the connection between collective behaviors in ICT use and community benefit. Quantitative analyses enable systematic testing of relationships, disentangling mediating variables, generating measurable community impacts of ICT collective behaviors, and with a larger sized sample.

Further, any single refugee population is diverse and intersectional, having varying experiences with ICTs, and, in turn, collective behaviors and sense of community. Not everyone feels comfortable or has confidence in their ICT skills to assist another. Also, previous research with camp-based Syrian refugees in Jordan found collective behaviors vary by gender (Maitland and $\mathrm{Xu}, 2019$ ). Whether or not their findings translate to an urban context is as yet unknown.

Our study addresses this gap by a) quantifying the impact of collective behaviors on the established sense of community construct, and b) specifying mediating variables, namely self-efficacy and gender, to further clarify the mechanism of effect. Specifically, we address the research questions:

RQ1: How are collective behaviors with ICTs related to sense of community?

RQ2: How is ICT self-efficacy related to sense of community?

RQ3: How does gender impact the relationship between collective behaviors with ICTs and sense of community?

RQ4: How does gender impact the relationship between ICT self-efficacy and sense of community?

Thus, our contribution expands the existing knowledge on the community-level impacts of refugee ICT use and complements existing qualitative scholarship by clarifying the mechanisms of the effect of collective behavior in ICT use on community belonging. 
We begin this paper with an examination of the background literature surrounding ICTs and social impacts, contextualizing it to the experiences of urban refugees. Then, we present our research methods, including design, sampling and data collection, validation of measures, and data analysis. We follow this section by presenting our findings and a discussion of those findings, and their implications for the social impacts of ICT use and urban refugees. We close this paper with a discussion of limitations, future directions, and a brief conclusion.

\section{Background Literature}

The Social Role of ICTs for Refugees

Recent scholarship on the impact of ICTs on the lives of refugees identifies benefits for accessing information (Shuva, 2020), maintaining anonymity while accessing resources (Kang et al., 2017), accessing essential services (Coles-Kemp and Jensen, 2019), and supporting and re-valorizing cultural norms (McCaffrey and Taha, 2019). ICTs of course are known for their ability to connect people at a distance, which can have profound emotional and psychological impacts for refugees, especially as those devices become more and more sophisticated: Leurs' (2019) study of refugees' ICT use illustrated the emotional highs and lows of maintaining familial and friendship bonds at a distance following flight. This emotional and psychological impact was echoed by Shah, Hess, \& Goodkind (2019), illustrating the emotional benefit and emotional toll of ICTs as a means of maintaining familial connection during separation due to displacement.

These impacts are the result of ICT's capacity to fulfill functions in social spaces that are limited or absent for refugees. Providing the means for transnational connection fulfills a void of control over one's life (Gough and Gough, 2019), or compensating for numerous spheres of social activity such as learning or interaction (Lintner, 2020). As this implies, community and social level impacts of ICTs are likewise present, as noted in Kaufmann's (2018) study of Syrian refugees in Vienna. The research demonstrated refugees' dependence on smartphones for various practices, most notably overcoming physical 
distance to maintain regular contact with friends and family (pp. 892-893). The author provides recommendations for assisting refugees in the interest of social integration. Kutscher \& Kress's (2018) study of refugee children in Germany likewise illustrated the value of digital technologies in maintaining relationships, but also forging new ones as well as digital technology's ability to support social involvement and social orientation. We are beginning to understand the positive social and community level implications of ICT use beyond just the individual refugee.

Once ICT usage is conceptualized beyond just the digital world by exploring its place within local cultural and social fabrics, new considerations begin to emerge. For instance, refugees use ICTs to avoid the difficulty of face-to-face encounters with the local community (Aléncar and Tsagkroni, 2019, p. 190). Such use hinders social integration. At the same time, pre-existing familial and relationship structures influence ICT-mediated communication, as shown by Fesenmaier's (2019) findings of the way communication at distance integrates with social factors like family structure (pp. 107-129). ICTs, therefore, function socially not just within digital spaces, but in physical ones as well, between collocated individuals. Rothenberger, Elmezeny, \& Wimmer's (2019) qualitative study of refugees in Germany showed that ICT use is an inherently social activity: sharing of media, sharing of games, and communal use of devices all constituted ICTs' place within the social fabric, usages that were subject to changes in family structure as well. Hussain, Safir, Sabie, Jahangir, \& Ahmed (2020) showed that these social interactions around ICTs extend beyond the family unit, finding that sharing of devices and equipment like SIM cards between refugees and the host community was suggestive of solidarity, especially considering that these strategies were employed to circumvent restrictions on ICT ownership by refugees (pp 7-8).

One form of collective behavior is providing assistance, which commonly takes the form of "intermediated actions" whereby one person undertakes technical activities on behalf of another (Parikh and Ghosh, 2006; Sambasivan et al., 2010). Lipset's (2018) study found that a crucial aspect of social practices with ICTs is assisting others, framed within that 
community's moral economy of transactions (pp. 28-30). Correa (2014) found providing assistance to have important social and personal benefits, including sustaining assistance reciprocity in their community, as well as basic skill building such as literacy development. Reciprocity, as a motivator, functions within both sharing and assisting, in theory connecting these collective behaviors to individual, psychological impacts on their perceptions of their community. This scholarship has built the possibility of a theoretical connection between assistive behavior and positive community impact through qualitative means, but this leaves a complementary gap for quantitative tests of this relationship. Given the intuition that providing assistance has a positive impact on community and social factors, we hypothesize:

Hla: Providing assistance with ICTs is positively related to sense of community.

Another form of collective behavior with ICTs that is closely related to providing assistance is sharing. The sharing of SIM cards indicates a wider form of collective behaviors, specifically the sharing of ICTs. Burrell (2010) defined mobile phone sharing as the "informal, non-remunerative resource distributing activities where multiple individuals have a relationship to a single device as a purchaser, owner, possessor, operator and/or user" (p. 30). Sharing itself is a deeply culturally ingrained practice, and therefore sharing of ICTs is subject to social factors. Lipset (2018) explored mobile phone sharing in Papua New Guinea, describing a moral imperative to participate in sharing, based on collective reciprocities. Komen (2015) similarly described the culturally embedded nature of sharing, identifying notions of trust and friendship, in addition to the strategies that sharers employ to circumvent resource shortcomings, such as in data allotments. This moral economy plays a crucial role in sharing behaviors, providing individual motivations within a social system built for collective benefit. Ahmed et al., (2017) also pointed to the power dynamics at play in device sharing, another reflection of pre-existing social structures and practices, illustrating that benefits may not be equally shared within these arrangements, most notably with different genders (p. 8). Paralleling scholarship in assisting with ICTs, this qualitative scholarship implies a positive connection between 
sharing and social impact. A quantitative examination fills a complementary gap in this scholarship, and so we hypothesize:

H1b: Sharing ICTs is positively related to sense of community.

Broadly speaking, qualitative studies, which form the vast majority of this extant scholarship, have illustrated the prevalence of social and community impacts of collective behaviors with ICTs. However, there is a lack of quantitative evidence of these impacts, given identifiable forms of collective behavior, and hence produce a complementary gap. Growing scholarship using mixed and quantitative methods of ICT use by refugees provide an opportunity to explore the connections between collective behaviors with ICTs and community-level impacts. Xu \& Maitland (2017) implemented an asset-based intervention program with Syrian refugees in the Za'atari Refugee Settlement, reporting positive impacts on individual sense of community. However, those findings were based on posttest only data. Using survey data from a different Za'atari sample, they explored the determinants of collective behaviors with ICTs (Maitland and Xu, 2019), crucially hinting at the potential for implications for sense of community (Xu and Maitland, 2019). Following from this scholarship that identifies sharing and providing assistance as constitutive elements of ICT collective behaviors, we explore these hypotheses to broadly examine the relationship between collective behaviors and sense of community, and answer research question 1 (RQ1).

\section{ICT Self-Efficacy}

Albert Bandura's concept of self-efficacy - "judgements of how well one can execute a course of action required to deal with prospective situations" (Bandura, 1982, p. 122) - has been shown to influence ICT use in a variety of ways, for instance, the capacity to learn in computer-based environments (Moos and Azevedo, 2009; Tsai et al., 2011), using ICTs to access information (Lim et al., 2011), or more generally the ICTs themselves (Olivier and Shapiro, 1993). Since collective behaviors with ICT assumes competency with these technologies, we anticipate ICT self-efficacy may influence the relationship between ICT 
collective behaviors and sense of community. This stems from extant scholarship showing self-efficacy's potential influence on community factors, but has been limited to contexts arguably very different than urban refugees, for example in schools or entirely online.

The influence of ICT self-efficacy, as a distinct form of self-efficacy (Musharraf et al., 2019), on community factors has been explored mostly indirectly. Shea \& Bidjerano (2010, 2012) explored the role that ICTs play in a 'blended' learning environment (composed of both in-person and online educational components) in supporting a 'community of inquiry.' Further explored by Cho, Kim, \& Choi (2017), they found quantitative evidence that suggested self-regulated learning in online learning likewise supported outcomes in a community of inquiry. The development of self-efficacy in the learning process represents an explicit component in community impacts, but the role of a student's self-efficacy with the tools needed for online or blended learning and its relationship with the community impacts reported are not directly explored.

Relatedly, there has been some limited scholarship on ICT tool usage and community impacts, such as the development of a sense of virtual community (Blanchard, 2004; Koh et al., 2003). More recent work by Kutscher \& Kress extends this scholarship by suggesting that online communities like Facebook can play a role in refugee communities beyond online settings, but are subject to one's ability to use those platforms: “...not every [refugee] interviewee was able to create a Facebook account, although it is regarded as vital by all of the interviewees as a basic means of contact with lost relatives and friends over long distances" (Kutscher \& Kress, 2018, p. 6). The degree to which ICT self-efficacy can affect community factors, as an evolution of the scholarship connecting virtual to physical communities, remains largely unquantified.

Informed by a) scholarship that identifies that ICT know-how can support community functionings (Cho et al., 2017; Shea and Bidjerano, 2010, 2012); and b) the potential for positive community interaction in physical spaces supported by one's self-efficacy, suggested by Kutscher and Kress (2018) (albeit restricted to online settings), we hypothesize that: 
H2: ICT self-efficacy is positively related to sense of community.

Gender, Sense of Community, and ICTs

Increasing access and use likewise cuts across gender. This introduces the possibility of differential experiences with ICTs, as social features of ICT use is a reflection of the cultural context within which use is embedded. Robins (2002) describes this milieu of preexisting factors as a "web of contingencies" (p. 236), potentially ranging from the politicaleconomic to the social and cultural. Inherent in these contingencies are gender norms that produce these differential experiences with ICTs.

Indeed, it is a web of contingencies that impact the gendered use of mobile phones. Although popular conceptions of ICTs view them as emancipatory, there has been significant scholarship identifying constraints for women. Gender-specific barriers limit equal access to ICTs (Dodson et al., 2013; Geldof, 2011; Gillwald et al., 2010; Summers et al., 2020; Wyche and Olson, 2018) as well as producing gendered patterns of ICT use (Ahmed et al., 2017; Summers et al., 2020; Wyche and Olson, 2018). These social conditions express pre-existing gendered power-hierarchies (Ahmed et al., 2017; Hafkin and Huyer, 2008; Summers et al., 2020), which can likewise have differentiating effects on any relationship between ICT use and individual sense of community. Maitland \& Xu (2019) reported differences in collective behaviors between the genders, citing cultural factors, but also speaking to the inter-personal relationships and device types as having an impact as well.

Any exploration of the social impacts of ICTs must engage the potential for gender-based differences in impact. Given the previously proposed relationship between providing assistance and sharing with ICTs and sense of community that we are focused on testing ( $\mathrm{H} 1$ and $\mathrm{H} 2$, respectively), as well as the extant scholarship suggesting differences, we hypothesize that gender has a significant impact on these relationships. We seek to test this through an examination of interaction effects: 
H3a: There is a significant interaction effect of gender on providing assistance with ICTs and sense of community relationship.

H3b: There is a significant interaction effect of gender on the sharing with ICTs and sense of community relationship.

Testing of these hypotheses will connect our analysis to the broader notion of gender's impact on the relationship between both components of collective behaviors, providing assistance and sharing, and sense of community, thereby answering research question 3 (RQ3).

The extant scholarship has also shown the differentiation of genders with regards to selfefficacy, and like the contrasting empowerment/disempowerment narratives of gender and social embeddedness of ICTs, it is a mixed bag. Tømte \& Hatlevik (2011) found that, in Norway, women report higher overall self-efficacy in ICT internet tasks than their male Norwegian counterparts. On the other hand, Olaitan (2018) reported that, in Nigeria, men had higher perceived ease of use and usefulness of a mobile phone than women. Sabie \& Ahmed's (2019) study of refugees in Canada echoed these difficulties for women as they tended to fall behind men in terms of using ICTs for resources such as social services or information, due to several factors including cultural issues, but not accounting for selfefficacy in their qualitative analysis.

While there are substantial quantitative studies of gender and technology self-efficacy, the impacts on community have only been hinted at through the role of societal norms (e.g. Huffman et al., 2013), gendered learning and use (e.g. He and Lee, 2009; Jaradat et al., 2018), or the role of familial and peer support (e.g. Vekiri and Chronaki, 2008). Given the possible impact of both collective behaviors with ICTs and ICT self-efficacy on sense of community, differences in how genders encounter these two predictors may lead to differential impacts on their sense of community. Informed by a) the intuition that genderbased differences in self-efficacy can lead to differences in the social impact of ICT use, and b) the previously identified gender-based differences in ICT based self-efficacy 
(Olaitan, 2018; Sabie and Ahmed, 2019; Tømte and Hatlevik, 2011), we hypothesize that gender has a significant impact on the relationship between ICT self-efficacy and sense of community. We seek to test this through an examination of an interaction effect:

H4: There is a significant interaction effect of gender on the ICT self-efficacy and sense of community relationship.

By testing this hypothesis, we seek to contribute to the understanding of gender's impact on the relationship between self-efficacy and community factors, where the role of ICT self-efficacy has only been hinted at in the extant quantitative scholarship (He and Lee, 2009; Huffman et al., 2013; Jaradat et al., 2018; Vekiri and Chronaki, 2008). Therefore, we test $\mathrm{H} 4$ to answer research question 4 (RQ4).

\section{Research Methods}

Research Design

To test our hypotheses and answer our research questions, we used a quantitative, survey study methodology (see "Measures" for more), using a sequence of regression models to analyze the data and offer conclusions. In total, we used 4 multiple regression models to test various scale conceptions of collective behavior and inclusion of interaction effects, per our hypotheses and questions (see "Data Analysis" for more information). We collected our survey data from urban refugees in two cities in Rwanda, using a stratified random sampling procedure to construct our sample in conjunction with UNHCR (see "Sampling and Data Collection” for more information) (Watt and Berg, 2002, pp. 70-71).

We chose Rwanda out of convenience, due to contacts developed with UNHCR during a single prior trip to the country. This relationship builds upon previous relationships with UNHCR field offices in other countries. As a refugee-hosting country, Rwanda is similar to its East-African neighbors, having hosted refugees from nearby countries for over two decades, as well as supporting more recent influxes (for example Burundi). Refugees are housed in several settlements in addition to urban communities (UNHCR, 2019a). As of 2017 , the country hosts 172,706 refugees overall, with approximately $20 \%$ living in urban 
environments (UNHCR, 2017). The data used in this analysis were collected as part of a larger study of an ICT training program, involving a pre-and post- test design. Here, we use only the pre-test data, thereby insulating our results from any possible effects of the training intervention.

We conducted this study in cooperation with UNHCR with approval from the Rwandan Government. As detailed below, we devised the sampling frame from UNHCR's proprietary database, which provided contact information for recruitment. Programmatic priorities of UNHCR dictated the study be conducted with urban refugees in two cities: Kigali and Huye. Given differences in their size and population density, with Kigali being greater on both, the two cities offer potential diversity on key variables.

\section{Sampling and Data Collection}

The sampling frame consisted of refugees registered with UNHCR, indicating residency in Kigali and Huye, over 18 years of age, and providing a mobile phone number at which they could be reached, which is nearly all refugees. Within the sampling frame, we constructed a stratified random sample based on the participants' gender, location within the city, and nationality, to ensure that representation of particular demographic groups were adequately represented in our sample, particularly gender (Watt and Berg, 2002, pp. 70-71). We contacted potential subjects, who gave consent for participation via their mobile phones. As compensation, they were paid for filling out the survey, which was administered in person via pen and paper. Given budgetary limitations, the sample size was limited, resulting in 71 subjects, with 52 from Kigali and 19 from Huye. The sample consists of 36 men and 35 women, with the majority hailing from Burundi (62), and the remaining 9 from the Democratic Republic of the Congo (DRC).

The Burundian refugees came to Rwanda fleeing ongoing violence and corruption. The situation, since 2015, has caused the deaths of hundreds and the forced migration of hundreds of thousands (Laer, 2017). Likewise, participants from the DRC fled internal conflict, violence, and insecurity (UNHCR, 2019b). 


\section{Measures}

Our survey questionnaire included the 24-item Sense of Community Index (SCI-2) (Chavis et al., 2008), 5 items of a self-developed ICT collective behaviors scale ( 2 items measuring sharing ICTs and 3 items measuring providing assistance with ICTs), and an 8-item selfdeveloped ICT self-efficacy scale customized to a low-income context and drawn from research on internet self-efficacy (Eastin and LaRose, 2000; Livingstone and Helsper, 2010; Yi and Hwang, 2003). We also collected demographic variables via single-item measures for age, gender, years of education, years since moving to Rwanda, and their city of residence during the time of the study.

While we elected to measure sense of community via the SCI-2 scale, there is an ongoing debate about whether the constructs of sense of community ought to be considered universal or context-specific (Hill, 1996). In effect, this produced two different strands of measurement: the development and measure of context-specific sense of community (e.g. Long \& Perkins, 2003; Rovai, 2002), and pursuit of a universal SCI metric (Chavis et al., 2008). Given the fact that the SCI-2 scale employed here was developed in western contexts, application to this unique context (to date, there have been no studies measuring sense of community for refugees, with the closest being studies of communities in the global south, for instance, Kerrigan, Telles, Torres, Overs, \& Castle, 2007) allows us to explore whether this scale appropriately captures the refugee experience, and shed light on this debate.

Although there are many scales for self-efficacy that refer to more specific applications, these approaches may not be as relevant for use in resource-constrained contexts. Thus, our conceptualization of ICT self-efficacy is geared toward assessing a wider range of skills, an approach that is suited to working with refugees since a broader conception of ICT self-efficacy does not seek to examine skills that would be considered advanced due to domain specificities, such as self-efficacy with regards to information evaluation, security, and privacy (Musharraf et al., 2019). For instance, whereas many people have 'feature phones,' which allow voice calls, text, and some data-related functions (for 
example USSD), many still lack smartphones, making use of mobile applications and the internet a more advanced skill. Additionally, many 'mobile-only' users do not use email, and hence this can also be seen as an advanced skill. In low resource contexts, advanced domain ICT self-efficacies may be unlikely to be found, so a broader approach is called for.

As previously stated, participants originally hailed from either Burundi or the Democratic Republic of the Congo (DRC). Accordingly, the survey was provided in Kinyarwanda and English, with verbal assistance provided in French, as well as support from a translator conversant in all three languages.

\begin{tabular}{l|lll} 
& Mean (SD) & Skew (Kurt) & Frequency \\
\hline Age (Years) & $33.13(10.52)$ & $0.74(0.13)$ & \\
Education (Years) & $10.25(2.71)$ & $0.21(-0.12)$ & \\
Years in Rwanda* & $4.09(5.50)$ & $2.00(2.22)$ & \\
Location & & 19 \\
$\quad$ Huye & & 52 \\
$\quad$ Kigali & & \\
Gender & & 36 \\
$\quad$ Male & & 35 \\
$\quad$ Female & & 62 \\
Nationality & & 9 \\
$\quad$ Burundi & &
\end{tabular}

Frequencies, means, and skewness measures are shown in Table 1. Based on the skewness and kurtosis levels being outside the acceptable bounds of normality for the years in Rwanda demographic variable, we conducted a log-transformation of these measures. This resulted in acceptable levels of skewness and kurtosis within the $[-2,2]$ interval.

\section{Measurement Validation}

We evaluated the SCI-2 scale's adherence to 4 dimensions of community using a confirmatory factor analysis (CFA) with the lavaan package in R (Rosseel, 2012). However, the data did not conform to the theorized 4-factor structure (fulfillment of needs, membership, influence, and emotional connection. Specifically, the analysis found a 
comparative fit index $(\mathrm{CFI})=0.66$, and Tucker-Lewis index $(\mathrm{TLI})=0.62$, both beneath acceptable levels of model fit for a CFA (Parry, 2017). However, the overall scale reported an acceptable Cronbach's $\alpha(\alpha=0.88)$. Regardless, to align with the theory-based underpinnings of the construct we reduced the SCI-2 scale to 6 items, drawing three items from two of the four sense of community dimensions, fulfillment of needs and emotional connection. This composition of the sense of community measure resulted in improved model fit indices $(\mathrm{CFI}=0.91$, $\mathrm{TLI}=0.81)$, accounted for a reasonable $70.04 \%$ of the cumulative variance in the sample (Hair et al., 2009), and an acceptable level of internal consistency (Cronbach's $\alpha=0.79$ ).

Our self-developed ICT collective behavior scale consists of two dimensions: sharing and providing assistance with ICTs. The CFA of the two-factor collective behavior scale resulted in acceptable fit indices $(\mathrm{CFI}=0.985$, TLI $=0.962)$ and an acceptable level of internal consistency (Cronbach's $\alpha=0.73$ ). Separately, we evaluated our sharing ICTs and providing assistance with ICTs scales for internal consistency, finding that while providing assistance resulted in a good level of internal consistency (Cronbach's $\alpha=0.86$ ), internal consistency for sharing was low (Cronbach's $\alpha=0.4$ ). We noted however that sharing ICTs (and providing assistance with ICTs as well) ought to be considered formative constructs insofar as the construct is "fully derived from its measurement," that therefore we do not necessarily expect high correlations between items (Bollen and Lennox, 1991; Freeze and Raschke, 2007). Therefore, we note this internal consistency level and proceed with these as formative constructs.

To evaluate our ICT self-efficacy scale, we did not have a strong pre-established theoretical motivation to evaluate sub-constructs within the scale, so we examined inter-item correlations and internal consistency levels. The correlation table indicated that nearly all items were significantly correlated with each other, except for item \#8, which we elected to remove from the analysis as a result, leaving us with a 7-item scale. The Cronbach's $\alpha$ was reasonably high as well $(\alpha=0.82)$. 
We evaluated normality for all of our constructs examining skewness and kurtosis levels. Collective behaviors, its two sub-scales of sharing and providing assistance, and sense of community were within an acceptable $[-2,2]$ interval, but ICT self-efficacy was not. To accommodate this, we conducted a log-transformation, resulting in acceptable levels of skewness and kurtosis within the $[-2,2]$ interval.

\section{Data Analysis}

Informed by the method used by Nevo \& Chengalur-Smith (2017), we ran a regression analysis on four models. The first model (Model 1) tested the direct effects of the ICT collective behaviors and ICT self-efficacy on sense of community, exploring RQ1 and RQ2, the latter by testing H2. The second model (Model 2) included gender-based interaction terms to evaluate the impact of gender on the relationship between collective behavior and ICT self-efficacy with sense of community, exploring RQ3 and RQ4, the latter by testing H4. The third model (Model 3) separated collective behavior into its two constituent sub-concepts of providing assistance and sharing ICTs, and tested for their direct effects (as well as ICT self-efficacy) on sense of community, further exploring RQ1 by testing H1a and H1b. Finally, the fourth model (Model 4) included the gender-based interaction effects into the collective behavior separated model, further exploring RQ3 and RQ4 by testing H3a and H3b. 


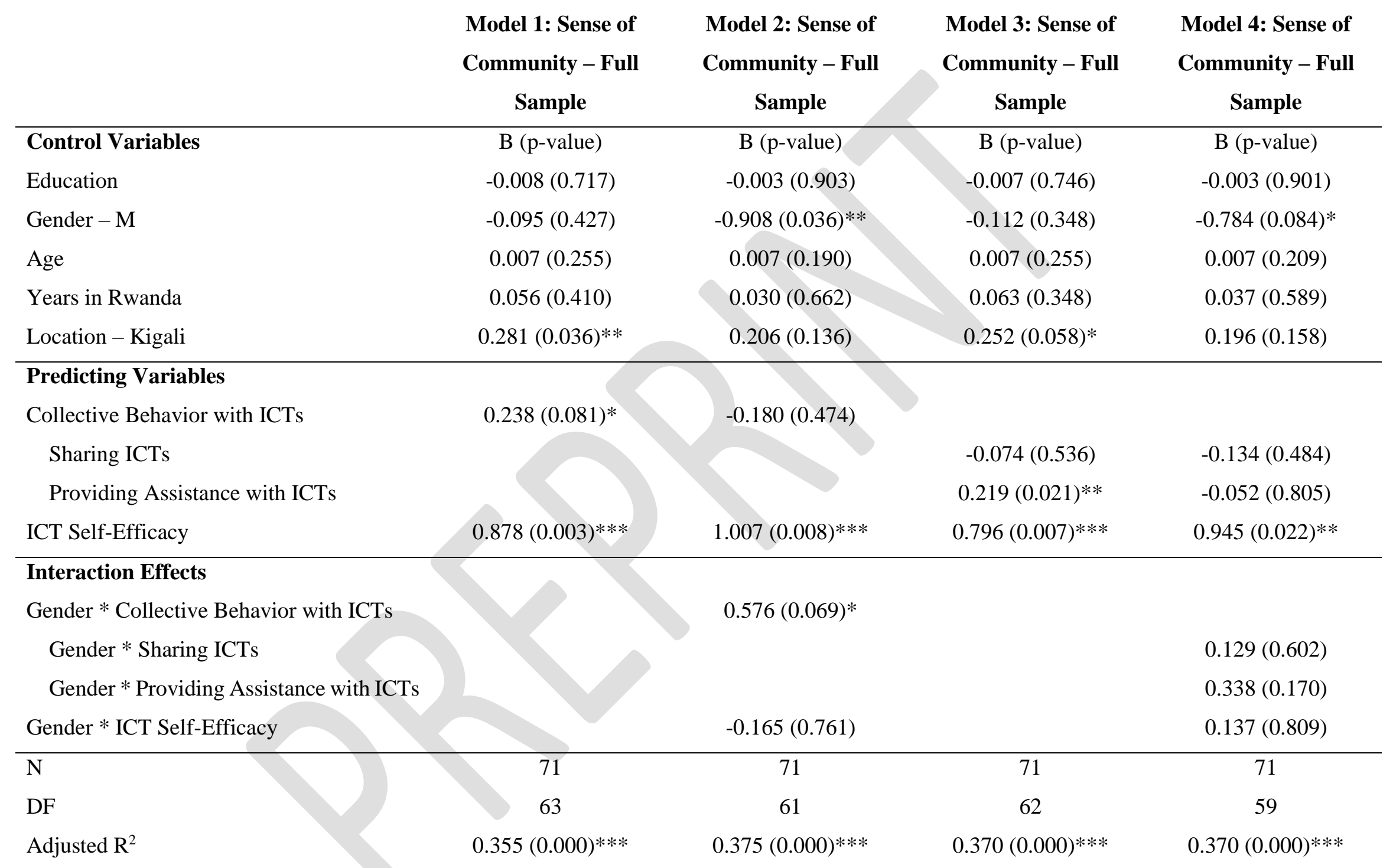

Notes: $* \mathrm{p}<0.1 ; * * \mathrm{p}<0.05 ; * * * \mathrm{p}<0.01$

Table 2: Results of Multiple Regression Analysis 


\section{Findings}

\section{Collective Behavior(s) and Sense of Community}

We examined the direct effects of research Model 1, and report those results in Table 2. The variance inflation factors (VIFs) for the model were all below 4, indicating no serious multicollinearity requiring correction (Hair, Black, Babin, \& Anderson, 2009, p. 193). The Breusch-Pagan test of homoskedasticity was insignificant at an $\alpha=0.1$ level, which suggested acceptable heteroskedasticity. By meeting the assumptions of linear regression (multivariate normality, multicollinearity, heteroskedasticity ("Assumptions of Multiple Linear Regression", 2009), we supported the overall robustness of our findings (Huntington-Klein, 2019).

Our regression analysis showed the overall model is significant, and that both collective behaviors and ICT self-efficacy were significant positive predictors of sense of community. Hence, there is positive support of RQ1: collective behaviors with ICTs have a relationship with sense of community. Additionally, hypothesis $\mathrm{H} 3$ was supported by these findings, likewise indicating positive support for RQ2: ICT self-efficacy has a positive relationship with sense of community.

Next, via Model 2, we tested interaction effects to explore the possible role of gender in the relationship between collective behaviors, ICT self-efficacy, and participants' overall sense of community. The VIFs were all below 4 and the Breusch-Pagan test of homoskedasticity was insignificant at an $\alpha=0.1$ level, meeting the multicollinearity and heteroskedasticity assumptions, respectively. The overall model was significant. We discovered that while the direct effect of collective behavior was no longer significant, the gender * collective behavior interaction effect was significant at an $\alpha=0.1$ level ( $p$-value $=0.069$ ). We visualized the interaction effect below (see Figure 1). The diagram shows an interaction effect between gender and collective behavior, whereby an increase in collective behaviors with ICTs is related to an increase in sense of community for the men in our sample, and an apparent decrease in sense of community for the women. Therefore, 
while we failed to reject the null hypothesis for $\mathrm{H} 4$ stipulating gender moderating the ICT self-efficacy and sense of community relationship (and in turn do not find evidence in RQ4), we provide evidence supporting RQ3: gender's role in ICT collective behaviors and sense of community. It is also worth noting that, comparing Models 1-4, Model 2 has the highest overall explanatory power (adjusted $\mathrm{R}^{2}$ ).

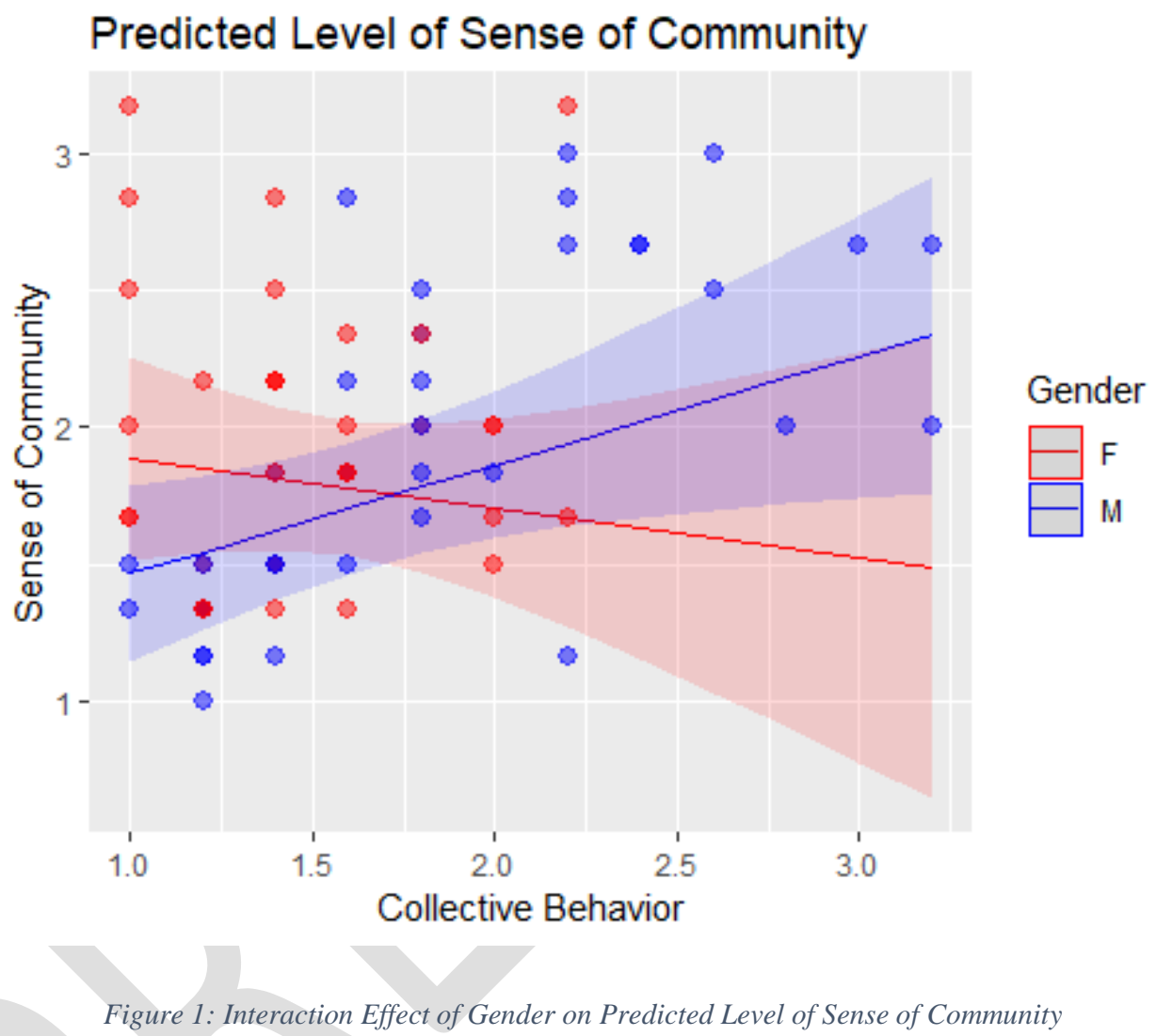

Providing Assistance and Sharing as ICT Collective Behaviors

Via Model 3, we explored the different sub-dimensions of collective behavior, sharing and providing assistance with ICTs. The VIFs were all below 4 and the Breusch-Pagan test of homoskedasticity was insignificant at an $\alpha=0.1$ level, meeting the multicollinearity and heteroskedasticity assumptions, respectively. Our regression analysis in Table 2 showed that providing assistance with ICTs had a significant positive relationship with sense of community, therefore providing support for H1A, but sharing ICTs did not bear a significant relationship, thus we failed to reject the null hypothesis for H1B. This suggests 
that providing assistance may be the principal driver of the collective behavior relationship to sense of community, which distinguishes it from sharing ICTs as a type of collective behavior.

We also explored this same separation of collective behavior dimensions with interaction effects via Model 4, introducing gender-based interactions for sharing and providing assistance in addition to ICT self-efficacy, allowing us to test for the impact that gender plays on the primary relationships introduced above. The VIFs were all below 4 and the Breusch-Pagan test of homoskedasticity was insignificant at an $\alpha=0.1$ level, meeting the multicollinearity and heteroskedasticity assumptions, respectively. Our regression analysis showed, similar to Model 2, the direct effects of ICT collective behaviors are no longer significant. Yet, unlike Model 2, none of the interaction effects were significant (or approached significance), failing to support hypotheses H3a and H3b.

\section{Gender Differences}

In addition to gender's effects within the research models presented above, we wanted to further explore potential differences in men's and women's perceptions and behaviors across all the variables. Via t-tests, we found that, although there were no statistically significant differences in levels of sense of community or ICT self-efficacy, men and women had significantly different levels of collective behavior with ICTs generally. When considering the two separate variables, only providing assistance demonstrated a difference.

\begin{tabular}{l|llll} 
Metrics & DF & Men & Women & t-test (p-value) \\
\hline Sense of Community & 69 & 1.949 & 1.952 & $0.025(0.981)$ \\
Collective Behavior w/ ICTs & 69 & 1.839 & 1.469 & $-3.063(0.003)^{* * *}$ \\
$\quad$ Sharing ICTs & 69 & 1.431 & 1.300 & $-1.173(0.245)$ \\
$\quad$ Providing Assistance with ICTs & 69 & 2.111 & 1.581 & $-3.015(0.004)^{* * *}$ \\
ICT Self-Efficacy & 69 & 0.555 & 0.513 & $-0.711(0.479)$
\end{tabular}

Notes: $* \mathrm{p}<0.1 ; * * \mathrm{p}<0.05 ; * * * \mathrm{p}<0.01$

Table 3: Results of t-test. 
This difference in collective behaviors motivated us to split the full sample by gender to further explore these differences. We re-tested the research models 1 and 3 with the split samples: first the regression model with the consolidated collective behavior scale, and next with the collective behavior scale separated into sharing and providing assistance with ICTs. Once again, the variance inflation (VIF) factors for both models were all below 4, indicating no serious multicollinearity requiring correction (Hair, Black, Babin, \& Anderson, 2009, p. 193).

The results, shown in Table 4, demonstrate that for men, collective behavior with ICTs maintained a significant positive relationship with sense of community, which agreed with the findings from the overall sample described above. On the other hand, however, neither ICT self-efficacy nor location remained significant predictors of men's sense of community. For women, ICT self-efficacy remained a positive predictor of sense of community, but neither collective behavior nor location remained as statistically significant predictors. It is also noteworthy that the explanatory power of the models (Adjusted $\mathrm{R}^{2}$ ) for men was .460, versus .220 for women.

The re-test of Model 3, with the disaggregated ICT collective behavior measures, shown in Table 4, further emphasized the differences between the men and women in the relationship between ICTs and sense of community. For men, the only significant predictor was providing assistance. For women, the only significant predictor was ICT self-efficacy. The difference in the explanatory power of these models also grew, with an adjusted $\mathrm{R}^{2}$ of .468 versus .196 , as compared to .460 versus .220 above.

There were also gender differences when examining the role of ICT self-efficacy as a predictor. ICT self-efficacy is a consistent predictor of sense of community when analyzing the full sample (see "Model 1: Sense of Community - Full Sample" in Table 2). However, splitting the sample by gender revealed that, while ICT self-efficacy remains a significant positive predictor of sense of community for women, this was not the case for the men (Table 4). 


\begin{tabular}{|c|c|c|c|c|}
\hline & $\begin{array}{c}\text { Model 1: Sense of } \\
\text { Community - Men } \\
\text { Only Sample }\end{array}$ & $\begin{array}{c}\text { Model 1: Sense of } \\
\text { Community - Women } \\
\text { Only Sample }\end{array}$ & $\begin{array}{c}\text { Model 3: Sense of } \\
\text { Community - Men } \\
\text { Only Sample }\end{array}$ & $\begin{array}{c}\text { Model 3: Sense of } \\
\text { Community - Women } \\
\text { Only Sample }\end{array}$ \\
\hline \multicolumn{5}{|l|}{ Control Variables } \\
\hline Education & $0.019(0.254)$ & $-0.024(0.511)$ & $0.020(0.507)$ & $-0.024(0.512)$ \\
\hline Age & $-0.001(0.956)$ & $0.011(0.148)$ & $-0.001(0.876)$ & $0.011(0.153)$ \\
\hline Years in Rwanda & $0.033(0.726)$ & $0.015(0.886)$ & $0.042(0.657)$ & $0.022(0.833)$ \\
\hline Location - Kigali & $0.193(0.327)$ & $0.200(0.330)$ & $0.174(0.375)$ & $0.197(0.346)$ \\
\hline \multicolumn{5}{|l|}{ Predicting Variables } \\
\hline Collective Behavior & $0.379(0.048)^{* *}$ & & & \\
\hline Sharing ICTs & & & $-0.021(0.895)$ & $-0.120(0.556)$ \\
\hline Providing Assistance with ICTs & & & $0.280(0.024)^{* *}$ & $0.010(0.966)$ \\
\hline ICT Self-Efficacy & $0.676(0.130)$ & $1.070(0.014)^{* *}$ & $0.631(0.155)$ & $0.995(0.035)^{* *}$ \\
\hline $\mathrm{N}$ & 36 & 35 & 36 & 35 \\
\hline DF & 29 & 28 & 28 & 27 \\
\hline Adjusted $\mathrm{R}^{2}$ & $0.460(0.000)^{* * *}$ & $0.220(0.040)^{* *}$ & $0.468(0.001)^{* * *}$ & $0.196(0.068)^{*}$ \\
\hline
\end{tabular}

Notes: $* \mathrm{p}<0.1 ; * * \mathrm{p}<0.05 ; * * * \mathrm{p}<0.01$

Table 4: Results of Regression Analysis on Gender-Split Sample. 


\section{Discussion}

Our findings provide insight into the fundamental nature of ICT collective behaviors, while at the same time shedding light on important community impacts. For each, relationships with fundamental ICT-related variables of self-efficacy and gender are explored.

\section{Theoretical Implications for Collective Behaviors and Sense of Community}

Extant scholarship on refugee technology use highlights its benefits, with some benefits being instrumental such as accessing resources and services (Coles-Kemp and Jensen, 2019; Kang et al., 2017), while others are more diffuse, such as psychosocial effects that focus on the connections supported through online or in-person relationships (Aléncar and Tsagkroni, 2019; Gough and Gough, 2019; Kaufmann, 2018; Kutscher and Kress, 2018). While the distant relationships of refugees warrant significant attention, refugees are embedded in relatively new, unfamiliar social relationships. Collective behaviors in ICT use among the physically co-located is another possible avenue for forming new ties or reinforcing existing ones. We extend the scholarship on refugee technology use by providing quantitative evidence of the relationships between ICT collective behaviors and sense of community, where community speaks to the new social embeddedness of refugee life. In doing so, we shed light on the fundamental nature of ICT collective behaviors, the role of self-efficacy, and gender.

First, our findings shed light on the question of whether ICT collective behaviors can be viewed as a general construct, or that the distinct behaviors should be treated separately. Existing theory in altruism and shared trauma (Hartman and Morse, 2018; Staub and Vollhardt, 2008) motivate a combined construct, but our findings illustrate two differences that emerge between sharing and providing assistance: a) between genders, and b) in their relationship with sense of community, reflecting differences in both demographics and effects. These differences are supported in part by Maitland \& Xu (2019), where they reasoned that sharing is driven more by the value of the asset (mobile handset, SIM card) as compared to providing assistance. The failure to reject the null hypothesis for the 
relationship between sharing and sense of community while simultaneously rejecting the null hypothesis for providing assistance and sense of community reinforces this distinction. In particular, it suggests that when a behavior is driven by the value of the central asset, it has fewer community benefits, whereas providing assistance may speak more to altruistic behaviors and be more connected to community. These findings should compel scholars exploring the collective behavior construct to not take these intra-construct differences for granted, particularly what underlies distinct forms of collective behaviors.

\section{Gender and the Relationship between Collective Behaviors and Sense of Community}

When it comes to the relationship of collective behaviors with sense of community, we find only providing assistance is a significant predictor. However, the fact that this positive relationship only existed for men suggests that certain demographic groups may not receive the same level of community benefit from social ICT use. Scholars that explore theories on the social impacts of ICTs, especially those focusing on refugees (e.g. Gough \& Gough, 2019; Kaufmann, 2018; Kutscher \& Kress, 2018; Lintner, 2020), must necessarily engage the social and cultural factors to properly conceptualize the meaning of their findings (something we admittedly do not do within the context of this particular study). Future research in this domain should explicitly examine the social and cultural factors that underlie the social impacts of ICTs to better understand their differential impacts.

Existing scholarship on gender and ICTs illustrates the angles through which ICTs can be used to reinforce a variety of socio-cultural factors, including access (Dodson et al., 2013; Geldof, 2011; Gillwald et al., 2010; Summers et al., 2020; Wyche and Olson, 2018), patterns of use (Ahmed et al., 2017; Summers et al., 2020; Wyche and Olson, 2018), and power hierarchies (Ahmed et al., 2017; Hafkin and Huyer, 2008; Summers et al., 2020). Our findings suggest similar forces are at play in our sample: while an increase in collective behaviors is related to an increased sense of community with men, for women, the same increase is associated with a decrease in sense of community. Kumar (2015) provides a potential explanation from research in India that found that displaying expertise violates patriarchal norms, suggesting negative community impacts. 
Findings from Maitland and Xu (2019) with camp-based refugees in Jordan illustrated the longer-term impacts of this condition, discovering that aspects of collective behaviors with ICTs (in the case of the related study, providing assistance with ICTs) was positively related to interest in future internet activities across both men and women. They therefore indicate that the differential impacts of collective behaviors like providing assistance may very well persist into the future, further widening the divide of differing impacts on sense of community. Such patriarchal norms are reflected in Burundian society (Basse and Kwizera, 2017), where the bulk of our sample originates.

Additionally, separation of the sample by gender and re-testing the regression models illustrates a substantial difference in the explanatory power of the models (Table 4). This difference in model performance implies that there are other factors at work for predicting sense of community for the women in our sample. This suggests a more complex relationship with technologies for women in patriarchal societies, perhaps corroborating findings from Charles et al. (2020) that described the numerous strategies and tactics employed by women in supporting elections in a hyper-masculine environment. For scholars, this suggests that working in situations where power asymmetries exist between demographic groups are likely to find more complex socio-technical interactions with ICTs with the disempowered, with community-level implications.

\section{The Role of ICT Self-Efficacy}

The positive relationship between ICT self-efficacy and sense of community contributes to the relative lack of scholarship on the relationship between community impacts and selfefficacy with ICTs by validating this relationship explicitly, as opposed to the implicit assumption of expertise in tool usage (Blanchard, 2004; Koh et al., 2003). This finding also provides quantitative evidence to support Kutscher \& Kress's (2018) qualitative findings on Facebook usage, providing multi-method triangulation (Williamson \& Johanson, 2013, p. 511). 
Our sample did not display a significant interaction effect of gender on the significant relationship between self-efficacy and sense of community, which suggests that this relationship is unaffected by the gender of the participant. We interpret this to suggest the robustness of the impact of technological self-efficacy on community factors.

However, these findings also suggest differentiation by gender: despite comparable levels of self-reported ICT self-efficacy, men reported significantly higher instances of providing assistance. This begs the question - why would women who are confident in their technological skills hesitate to offer assistance? We believe the answer may lie in perceptions of expertise: are men asked more frequently to help with ICTs than women? This accords with previous findings suggesting that women are perceived to have less expertise in ICTs than they actually have (Thomas-Hunt and Phillips, 2004), likely exacerbated within patriarchal societies like Burundi where the bulk of our participants hail from (Basse and Kwizera, 2017).

This observation is particularly relevant for women in this sample, as self-efficacy was the only significant predictor of sense of community for women, whereas for men it was collective behaviors (Table 4). This suggests that, for women, the process of building selfefficacy in ICTs and their empowerment lends itself to community belongingness, despite displaying these skills in a social setting less than their male peers. This indicates different ways certain demographics build community value with skills: for women, as a form of individual empowerment in a patriarchal society; for men, as an opportunity to socially display expertise, within that patriarchal society, and reflects the aforementioned findings from Kumar (2015). As women risk falling behind men in self-efficacy in certain circumstances (Olaitan, 2018; Sabie and Ahmed, 2019; Tømte and Hatlevik, 2011), the community impacts appear more profound for women than men. Informed by these findings, theorists exploring the relationship between self-efficacy and community aspects, for example, online communities (Blanchard, 2004; Koh et al., 2003; Kutscher and Kress, 2018) or community connectedness (Kutscher and Kress, 2018), can explore the values of 
different forms of building capacity suggested by gender: as a means of individual empowerment, or as a means of display.

\section{Policy Implications for Urban Refugees}

Our findings across the dimensions of this study have several policy implications. UNHCR policy on urban refugees has evolved considerably since 2009 when the agency and nongovernmental organizations began paying closer attention to urban refugees (UNHCR, 2012). While the development of policies that extend beyond the basic necessities of life towards the social and cultural fulfillment of urban refugees has been welcome, supporting organizations still struggle to work closely with urban refugees, as well as promote relationships with host community institutions (Crisp, 2017).

At the same time, access to basic services (e.g., healthcare, education) increasingly is dependent on first having access to mobile service and ICT devices (Coles-Kemp and Jensen, 2019; Kang et al., 2017; Shuva, 2020), a trend that matches increasing ICT penetration more broadly. The increasing use of ICTs to meet basic necessities represents a way for humanitarian actors to positively affect the social, cultural, and community fulfillment of urban refugees, provided certain contingencies are met. This study's findings shed light on these contingencies, arguing for policy that seeks to connect the use of ICTs, commonly conceptualized as the means of access for basic needs, to its more diffuse social and cultural benefits, thereby fulfilling a need in urban refugee life.

Specifically, such policies should promote ICT skills training programs supporting a range of beneficial outcomes. Often, such programs are designed to provide refugees with job skills, within larger livelihoods initiatives. Our research suggests an exclusive focus on economic benefits may be shortsighted and that a broader range of refugees can benefit, beyond those most likely to obtain formal employment. Also, capturing the benefits of ICT self-efficacy and its relationship with sense of community can provide important additional justification for these training programs, as well as fulfill community needs. Where ICT training programs are designed to promote collective behaviors, as opposed to courses 
taken individually online, our findings suggest the benefits to sense of community are more likely to develop.

Additionally, as noted by gender researchers (Cheung and Phillimore, 2017; Hunt, 2008; Koyama, 2015), programs and policies tend to be 'gender-neutral,' thereby masking the differences women face. The numerous gender-based differences observed in this study suggest that a gender-neutral perspective risks exacerbating pre-existing gender divides with regards to both social and technical considerations, and misses substantial opportunities to engage all genders in a way that inclusively speaks to their distinct lived experiences in their communities. Programs and policies must contend with the gender question in technology, as the implications have profound effects on the communities and individuals, for better or for worse.

Understanding the role of gender in refugee ICT programs requires 'gender analyses,' which take into account how gender intersects with other axes of inequity (Theobald et al., 2017) and implications of technology use among each refugee population. Such analyses must consider both home and host country contexts, as, for example, refugees fleeing from and to urban areas may live in a different cultural context from those fleeing from rural to urban areas. Such analyses should also take into account gender-based norms across a range of technological factors, from mobile phone ownership and access to specific uses (e.g., calling, texting, social media use, entertainment). Understanding the gendered nature of ICT use, as well as the types of collective behaviors and where they are enacted that are deemed socially acceptable, will be key to leveraging the potential benefits of these behaviors for sense of community.

\section{Limitations and Future Directions}

We note five limitations of this study, the first of which is our test of the SCI-2 scale with a relatively unique community (urban refugees in Kigali and Huye). While the use of the scale provided a vetted and well-recognized connection to theory and offered the potential for greater generalizability, its poor fit with our population uncovers a missed opportunity 
to fully conceptualize and test a refugee-specific measure of sense of community. Hence, future research should consider community characteristics intersecting with the Sense of Community's specific dimensions and then develop and test a new construct.

A second limitation is that our sample and data were not conducive to more sophisticated analytic techniques, in particular structural equation modeling (SEM). Our tests with SEM, which could have provided greater clarity in relationships between predictors, resulted in a low comparative fit index, a low Tucker-Lewis index, and a significant chi-square test, all indicating poor model fit (Kenney, 2020). Therefore, future quantitative analyses similar to ours should aim to test more sophisticated models.

A third limitation is an oddity in our results: while gender moderated the relationship between collective behavior with ICTs and sense of community, its interaction effect of providing assistance and sense of community, and sharing and sense of community, were both non-significant. The smaller sample size could potentially hide effects that are more prominent in the larger collective behavior scale. However, further exploration of this phenomenon is needed but is outside the scope of this study.

The fourth limitation stems from our exclusive use of quantitative data in the analysis of the gendered nature of ICT use and its effects. Greater insight might have been generated by a complementary qualitative study. In particular, future research might explore a more focused gender analysis, first engaging more deeply with the gender, technology, and technical assistance literature and then using ethnographic methods to more thoroughly analyze the relationships between technical assistance and sense of community among women refugees.

Lastly, we recognize our binary conceptualization of gender may contribute to systems that deny gender fluidity and continue to mask the lives, effects, and technology use behaviors of those with diverse gender identities. Future research on gender and technology use by refugees might employ a non-binary frame, however careful attention to social and cultural 
norms of the refugees themselves as well as the host community must be taken into account to ensure adequate protection of research subjects.

\section{Conclusion}

Our research examined the connection between ICT collective behaviors, gender, and sense of community among urban refugees in Rwanda. Our quantitative findings indicated collective behaviors are positively associated with sense of community, particularly providing assistance. However, this is primarily the case for men. Our gender-based interaction analysis showed increasing collective behavior actually decreased sense of community for women. We theorize this phenomenon is the result of the milieu of gender dynamics and hierarchies being expressed in ICT use, particularly in women's display of technological expertise in social settings. In turn, these circumstances generate different modalities of impacts on sense of community, as supported by our findings. Furthermore, while we observed no statistical difference in sense of community or ICT self-efficacy between men and women, for women, ICT self-efficacy was a significant predictor of sense of community, which was not the case for men. Together, these findings suggest an interplay between technology-based collective behaviors and self-efficacy that may not be equally experienced across all demographic groups.

Ultimately, this study's quantitative approach provides measurable evidence to themes of community and ICT that are commonly engaged via qualitative analyses. Most notably, we provide evidence suggesting the relationship between ICT collective behaviors and community is complex and moderated by gendered power dynamics. We explored these topics with a community of urban refugees, who serve as an extreme case, in which they may be more likely to engage in altruistic behaviors than non-refugees, and are more likely to have access to technologies than their rural and camp-based refugee counterparts. Therefore, our findings and their implications establish a baseline, particularly for research on communities in resource-constrained environments. Studies with non-refugees have established ICT collective behaviors' role in circumventing limited hardware availability, for instance, fewer mobile phones in a household than members. These findings are 
particularly important for scholars and organizations active in humanitarian relief and development, aiming to use technology to support individuals and communities, but understand doing so must address the complex web of contingencies. 


\section{References}

Ahmed, S.I., Haque, M.R., Chen, J. and Dell, N. (2017), "Digital privacy challenges with shared mobile phone use in bangladesh", Proceedings of the ACM on HumanComputer Interaction, ACM New York, NY, USA, Vol. 1 No. CSCW, pp. 1-20.

Alencar, A. (2020), "Mobile communication and refugees: An analytical review of academic literature", Sociology Compass, Wiley Online Library, pp. 1--13.

Aléncar, A.P. and Tsagkroni, V. (2019), "Prospects of refugee integration in the Netherlands: Social capital, information practices and digital media", Media and Communication, Vol. 7 No. 2 Refugee Crises Disclosed, pp. 184-194.

“Assumptions of Multiple Linear Regression”. (2009), Statistics Solutions: Advancement through Clarity, available at: https://www.statisticssolutions.com/assumptions-ofmultiple-linear-regression/ (accessed 15 January 2019).

Bandura, A. (1982), "Self-efficacy mechanism in human agency", American Psychologist, American Psychological Association, Vol. 37 No. 2, pp. 122--147.

Basse, Y.O. and Kwizera, J. (2017), Norms and Practices Impeding Gender Equality in Burundian Society, Dakar, Senegal, available at: http://careevaluations.org/wpcontent/uploads/Norms-and-practices-impeding-Gender-Equality-in-Burundi.pdf.

Best, M.L., Kollanyi, B. and Garg, S. (2012), "Sharing in Public: Working With Others in Ghanaian Cybercafés", Proceedings of the Fifth International Conference on Information and Communication Technologies and Development (ICTD '12), pp. 211-220.

Blanchard, A. (2004), "Blogs as virtual communities: Identifying a sense of community in the Julie/Julia project", Into the Blogosphere Rhetoric Community and Culture of Weblogs, pp. 1--12.

Bollen, K. and Lennox, R. (1991), “Conventional Wisdom on Measurement: A Structural Equation Perspective", Psychological Bulletin, Vol. 110 No. 2, pp. 305-314. 
Burrell, J. (2010), "Evaluating shared access: Social equality and the circulation of mobile phones in rural Uganda", Journal of Computer-Mediated Communication, Vol. 15 No. 2, pp. 230-250.

Charles, D.D., Meena, A., Lalvani, S., Akbar, S.Z., Siddarth, D. and Joyojeet Pal. (2020), "Performing Gender, Doing Politics: Social Media and Women Election Workers in Kerala and Tamil Nadu", ICTD '20 Proceedings of the Eleventh International Conference on Information and Communication Technologies and DevelopmentICT, Guayaquil, Ecuador, pp. 1--11.

Chavis, D.M., Lee, K.S. and Acosta, J.D. (2008), "The Sense of Community (SCI) Revised: The Reliability and Validity of the SCI-2", The 2nd International Community Psychology Conference, pp. 2-6.

Cheung, S.Y. and Phillimore, J. (2017), "Gender and Refugee Integration: A Quantitative Analysis of Integration and Social Policy Outcomes", Journal of Social Policy, Vol. 46 No. 2, pp. 211-230.

Cho, M.-H., Kim, Y. and Choi, D. (2017), “The effect of self-regulated learning on college students' perceptions of community of inquiry and affective outcomes in online learning", The Internet and Higher Education, Elsevier, Vol. 34, pp. 10-17.

Coles-Kemp, L. and Jensen, R.B. (2019), “Accessing a New Land: Designing for a Social Conceptualisation of Access", Proceedings of the 2019 CHI Conference on Human Factors in Computing Systems, Association for Computing Machinery, New York, NY, USA, pp. 1-12.

Correa, T. (2014), "Bottom-Up Technology Transmission Within Families: Exploring How Youths Influence Their Parents' Digital Media Use With Dyadic Data”, Journal of Communication, Vol. 64, pp. 103-124.

Crisp, J. (2017), “An Inside Account of UNHCR's Urban Refugee Policy”, News Deeply, April, available at: 
https://www.newsdeeply.com/refugees/community/2017/04/14/an-inside-account-ofunhcrs-urban-refugee-policy.

Dodson, L., Sterling, S. and Bennett, J. (2013), "Minding the gaps: cultural, technical and gender-based barriers to mobile use in oral-language Berber communities in Morocco", Proceedings of the Sixth International Conference on Information and Communication Technologies and Development (ICTD 2013), pp. 79-88.

Eastin, M.S. and LaRose, R. (2000), "Internet Self-Efficacy and the Psychology of the Digital Divide”, Journal of Computer-Mediated Communication, Vol. 6 No. 1.

Fesenmaier, M.A. (2019), Migrants' Reported Use of Communication Behaviors That Enact Family across Distance, University of Washington.

Freeze, R.D. and Raschke, R.L. (2007), “An Assessment of Formative and Reflective Constructs in IS Research", ECIS, pp. 1--12.

Geldof, M. (2011), "Earphones are not for women: Gendered ICT use among youths in Ethiopia and Malawi”, Information Technologies \& International Development, Vol. 7 No. 4 , pp. $69-80$.

Gillwald, A., Milek, A. and Stork, C. (2010), "Towards Evidence-based ICT Policy and Regulation: Gender Assessment of ICT Access and Usage in Africa”, Research ICT Africa, Vol. 1 No. 5, pp. 1-39.

Gough, H.A. and Gough, K. V. (2019), "Disrupted becomings: The role of smartphones in Syrian refugees' physical and existential journeys", Geoforum, Elsevier, Vol. 105, pp. 89-98.

Hafkin, N.J. and Huyer, S. (2008), "Women and Gender in ICT Statistics and Indicators for Development", Information Technologies and International Development, Vol. 4 No. 2, pp. 25--41.

Hair, J.F., Black, W.C., Babin, B.J. and Anderson, R.E. (2009), Multivariate Data Analysis, Prentice Hall, Upper Saddle River, NJ. 
Hartman, A.C. and Morse, B.S. (2018), "Violence, empathy and altruism: Evidence from the Ivorian refugee crisis in Liberia", British Journal of Political Science, Cambridge University Press, pp. 1-25.

He, J. and Lee, F. (2009), “Are men more technology-oriented than women? The role of gender on the development of general computer self-efficacy of college students", 15th Americas Conference on Information Systems 2009, AMCIS 2009, Vol. 8 No. 2, pp. 5546-5557.

Hill, J.L. (1996), "Psychological Sense of Community: Suggestions for Future Research", Journal of Community Psychology, Vol. 24 No. 4, pp. 431-43.

Huffman, A.H., Whetten, J. and Huffman, W.H. (2013), "Using technology in higher education: The influence of gender roles on technology self-efficacy", Computers in Human Behavior, Elsevier Ltd, Vol. 29 No. 4, pp. 1779-1786.

Hunt, L. (2008), "Women Asylum Seekers and Refugees: Opportunities, Constraints and the Role of Agency", Social Policy and Society, Vol. 7 No. 3, pp. 281-292.

Huntington-Klein, N. (2019), "Robustness Tests: What, Why, and How", available at: http://www.nickchk.com/robustness.html (accessed 15 July 2020).

Hussain, F., Safir, A.H., Sabie, D., Jahangir, Z. and Ahmed, S.I. (2020), "Infrastructuring Hope: Solidarity, Leadership, Negotiation, and ICT among the Rohingya Refugees in Bangladesh", Proceedings of the 2020 International Conference on Information and Communication Technologies and Development, Association for Computing Machinery, Guayaquil, Ecuador, pp. 1--12.

Jaradat, M.-I.R.M., Imlawi, J.M. and Al-Mashaqba, A.M. (2018), "Investigating the Moderating Effects of Gender and Self-Efficacy in the Context of Mobile Payment Adoption: A Developing Country Perspective", International Journal of Interactive Mobile Technologies, Vol. 12 No. 2, pp. 113-129.

Kang, J., Ling, R. and Chib, A. (2017), "Strategic Use of ICTs among North Korean 
Women Resettled in South Korea", Proceedings of the Ninth International Conference on Information and Communication Technologies and Development, Association for Computing Machinery, Lahore, Pakistan, pp. 1--5.

Kaufmann, K. (2018), "Navigating a new life: Syrian refugees and their smartphones in Vienna", Information, Communication \& Society, Taylor \& Francis, Vol. 21 No. 6, pp. 882-898.

Kenney, D.A. (2020), "Measuring Model Fit", available at: http://www.davidakenny.net/cm/fit.htm (accessed 7 July 2020).

Kerrigan, D., Telles, P., Torres, H., Overs, C. and Castle, C. (2007), “Community development and HIV/STI-related vulnerability among female sex workers in Rio de Janeiro, Brazil”, Health Education Research, Oxford University Press, Vol. 23 No. 1, pp. 137-145.

Koh, J., Kim, Y.-G. and Kim, Y.-G. (2003), "Sense of Virtual Community: A Conceptual Framework and Empirical Validation", International Journal of Electronic Commerce, Vol. 8 No. 2, pp. 75-94.

Komen, L. (2015), “'Here you can use it': Understanding mobile phone sharing and the concerns it elicits in rural Kenya", New Directions in Media Research, Vol. 1 No. 1, pp. 52-65.

Koyama, J. (2015), "Constructing gender: Refugee women working in the United States", Journal of Refugee Studies, Vol. 28 No. 2, pp. 258-275.

Kumar, N. (2015), “The gender-technology divide or perceptions of non-use?", First Monday, Vol. 20 No. 11, available at:https://doi.org/10.5210/fm.v20i11.6300.

Kutscher, N. and Kress, L.-M. (2018), "The ambivalent potentials of social media use by unaccompanied minor refugees", Social Media+ Society, SAGE Publications Sage UK: London, England, Vol. 4 No. 1, pp. 1--10.

Laer, T. Van. (2017), "Why Burundians continue to flee - African Arguments Why 
Burundians continue to flee - African Arguments", African Arguments, 24 August, available at: https://africanarguments.org/2017/08/24/why-burundians-continue-toflee/.

Leurs, K. (2019), "Transnational connectivity and the affective paradoxes of digital care labour: Exploring how young refugees technologically mediate co-presence", European Journal of Communication, SAGE Publications Sage UK: London, England, Vol. 34 No. 6, pp. 641-649.

Lim, S., Xue, L., Yen, C.C., Chang, L., Chan, H.C., Tai, B.C., Duh, H.B.L., et al. (2011), "A study on Singaporean women's acceptance of using mobile phones to seek health information", International Journal of Medical Informatics, Elsevier, Vol. 80 No. 12, pp. e189-e202.

Lintner, C. (2020), "Being (co-) present: Reflecting the personal and public spheres of asylum seeking in relation to connectivity", Ethnography, SAGE Publications Sage UK: London, England, Vol. 0 No. 0, pp. 1--23.

Lipset, D. (2018), “A Handset Dangling in a Doorway: Mobile Phone Sharing in a Rural Sepik Village (Papua New Guinea)", in Foster, R.J. and Horst, H.A. (Eds.), The Moral Economy of Mobile Phones, ANU Press, pp. 19--37.

Livingstone, S. and Helsper, E. (2010), "Balancing Opportunities and Risks in Teenagers' Use of the Internet: the Role of Online Skills and Internet Self-Efficacy", New Media \& Society, Vol. 12 No. 2, pp. 309-329.

Long, D.A. and Perkins, D.D. (2003), "Confirmatory Factor Analysis of the Sense of Community Index and Development of a Brief SCI", Journal of Community Psychology, Vol. 31 No. 3, pp. 279-296.

Maitland, C. and Xu, Y. (2019), "Collective Behaviors in Mobile Internet Access: An Exchange-Based Approach", Information Technologies \& International Development, Vol. 15, pp. 79-96. 
McCaffrey, K.T. and Taha, M.C. (2019), "Rethinking the digital divide: Smartphones as translanguaging tools among middle eastern refugees in New Jersey", Annals of Anthropological Practice, Wiley Online Library, Vol. 43 No. 2, pp. 26-38.

Moos, D.C. and Azevedo, R. (2009), "Learning with computer-based learning environments: A literature review of computer self-efficacy", Review of Educational Research, Sage Publications Sage CA: Los Angeles, CA, Vol. 79 No. 2, pp. 576-600.

Musharraf, S., Bauman, S., Anis-ul-Haque, M. and Malik, J.A. (2019), "General and ICT self-efficacy in different participants roles in cyberbullying/victimization among Pakistani university students", Frontiers in Psychology, Vol. 10, pp. 1-11.

Nevo, S. and Chengalur-Smith, I.S. (2017), 'Examining organizations' continued use of open source technologies: An institutional perspective", Information Technology and People, Vol. 30 No. 1, pp. 24-46.

Olaitan, A.W. (2018), "Socio-demographic factors that determine the usage of mobile phones in rural communities", The Journal of Social Sciences Research, Vol. 4 No. 2, pp. 16-23.

Olivier, T.A. and Shapiro, F. (1993), "Self-efficacy and computers.", Journal of ComputerBased Instruction, ERIC, Vol. 20 No. 3, pp. 81-85.

Parikh, T. and Ghosh, K. (2006), "Understanding and Designing for Intermediated Information Tasks in India", IEEE Pervasive Computing, Vol. 5 No. 2, pp. 32-39.

Parry, S. (2017), "Fit Statistics commonly reported for CFA and SEM", Cornell Statistical Consulting Unit: Cornell University.

Robins, M.B. (2002), “Are African women online just ICT consumers?”, Gazette: The International Journal for Communication Studies, Vol. 64 No. 3, pp. 235-249.

Rosseel, Y. (2012), Lavaan: An R Package for Structural Equation Modeling and More, available at: https://users.ugent.be/ yrosseel/lavaan/lavaanIntroduction.pdf. 
Rothenberger, L., Elmezeny, A. and Wimmer, J. (2019), “'YouTube helps us a lot.' Media repertoires and social integration of Iraqi and Syrian refugee families in Germany", Revue Française Des Sciences de l'information et de La Communication, Société Française de Sciences de l'Information et de la Communication, Vol. 17, available at:https://doi.org/10.4000/rfsic.6857.

Rovai, A.P. (2002), "Building sense of community at a dstance", International Review of Research in Open and Distance Learning, Vol. 3 No. 1, pp. 1-16.

Sabie, D. and Ahmed, S.I. (2019), "Moving into a technology land: exploring the challenges for the refugees in Canada in accessing its computerized infrastructures", Proceedings of the Conference on Computing \& Sustainable Societies, pp. 218-233.

Sambasivan, N., Cutrell, E., Toyama, K. and Nardi, B. (2010), "Intermediated Technology Use in Developing Communities", Proceedings of the SIGCHI Conference on Human Factors in Computing Systems (CHI '10), ACM, New York, NY, USA, pp. 25832592.

Shah, S.F.A., Hess, J.M. and Goodkind, J.R. (2019), "Family Separation and the Impact of Digital Technology on the Mental Health of Refugee Families in the United States: Qualitative Study", Journal of Medical Internet Research, JMIR Publications Inc., Toronto, Canada, Vol. 21 No. 9, pp. 1--13.

Shea, P. and Bidjerano, T. (2010), "Learning presence: Towards a theory of self-efficacy, self-regulation, and the development of a communities of inquiry in online and blended learning environments", Computers and Education, Elsevier Ltd, Vol. 55 No. 4, pp. 1721-1731.

Shea, P. and Bidjerano, T. (2012), "Learning presence as a moderator in the community of inquiry model", Computers and Education, Elsevier Ltd, Vol. 59 No. 2, pp. 316-326.

Shuva, N.Z. (2020), Information, Employment, and Settlement of Immigrants: Exploring the Role of Information Behaviour in the Settlement of Bangladesh Immigrants in 
Canada, University of Western Ontario.

Staub, E. and Vollhardt, J. (2008), "Altruism born of suffering: The roots of caring and helping after victimization and other trauma", American Journal of Orthopsychiatry, Wiley Online Library, Vol. 78 No. 3, pp. 267-280.

Summers, K.H., Baird, T.D., Woodhouse, E., Christie, M.E., McCabe, J.T., Terta, F. and Peter, N. (2020), "Mobile phones and women's empowerment in Maasai communities: How men shape women's social relations and access to phones", Journal of Rural Studies, Elsevier, Vol. 77, pp. 126--137.

Theobald, S., Morgan, R., Hawkins, K., Ssali, S., George, A. and Molyneux, S. (2017), "The importance of gender analysis in research for health systems strengthening", Health Policy and Planning, Vol. 32 No. Who 2016, pp. v1-v3.

Thomas-Hunt, M.C. and Phillips, K.W. (2004), "When what you know is not enough: Expertise and gender dynamics in task groups", Personality and Social Psychology Bulletin, Sage Publications Sage CA: Thousand Oaks, CA, Vol. 30 No. 12, pp. 15851598.

Tømte, C. and Hatlevik, O.E. (2011), "Gender-differences in Self-efficacy ICT related to various ICT-user profiles in Finland and Norway. How do self-efficacy, gender and ICT-user profiles relate to findings from PISA 2006", Computers and Education, Vol. 57 No. 1 , pp. 1416-1424.

Tsai, C.-C., Chuang, S.-C., Liang, J.-C. and Tsai, M.-J. (2011), "Self-efficacy in Internetbased learning environments: A literature review", Journal of Educational Technology \& Society, JSTOR, Vol. 14 No. 4, pp. 222-240.

UNHCR. (2012), The Implementation of UNHCR's Policy on Refugee Protection and Solutions in Urban Areas: Global Surve - 2012, Policy Development and Evaluation Service, available at:https://doi.org/10.1093/ijrl/eep028.

UNHCR. (2017), Participatory Assessment 2017, available at: 
https://www.unhcr.org/rw/wp-content/uploads/sites/4/2018/01/PA-2017REPORT.pdf.

UNHCR. (2019a), Rwanda Country Refugee Response Plan 2019-2020, available at: https://data2.unhcr.org/en/documents/download/69632.

UNHCR. (2019b), Democratic Republic of the Congo Refugee Crisis Explained, available at:https://doi.org/10.1163/9789004305052_026.

Vekiri, I. and Chronaki, A. (2008), "Gender issues in technology use: Perceived social support, computer self-efficacy and value beliefs, and computer use beyond school", Computers \& Education, Elsevier, Vol. 51 No. 3, pp. 1392-1404.

Walton, M., Marsden, G., Haßreiter, S. and Allen, S. (2012), "Degrees of Sharing: Proximate Media Sharing and Messaging by Young People in Khayelitsha", Proceedings of the 14th International Conference on Human-Computer Interaction with Mobile Devices and Services (MobileHCI '12), pp. 403--412.

Watt, J.H. and Berg, S. van den. (2002), "Chapter 6: Sampling”, Research Methods For Communication Science, Allyn \& Bacon.

Williamson, K. and Johanson, G. (Eds.). (2013), Research Methods: Information, Systems and Contexts, 1st ed., Tilde Publishing and Distribution, Pahran, Australia.

Wyche, S. and Olson, J. (2018), “Gender, Mobile, and Mobile Internet| Kenyan Women's Rural Realities, Mobile Internet Access, and 'Africa Rising", Information Technologies \& International Development, Vol. 14, pp. 33--47.

$\mathrm{Xu}, \mathrm{Y}$. and Maitland, C. (2017), "Mobilizing Assets: Data-Driven Community Development with Refugees", Proceedings of the Ninth International Conference on Information and Communication Technologies and Development (ICTD '17), ACM, New York, NY, USA, Lahore, Pakistan, pp. 1-12.

Xu, Y. and Maitland, C. (2019), "Participatory Data Collection and Management in LowResource Contexts: A Field Trial with Urban Refugees", ICTD '19 Proceedings of the 
Tenth International Conference on Information and Communication Technologies and Development, Ahmedabad, India, pp. 1--12.

Yi, M.Y. and Hwang, Y. (2003), "Predicting the Use of Web-based Information Systems: Self-Efficacy, Enjoyment, Learning Goal Orientation, and the Technology Acceptance Model", International Journal of Human Computer Studies, Vol. 59 No. 4, pp. 431-449. 